\title{
Haemodynamic changes during the apnoea test for diagnosis of brain death
}

Toshiya Ebata MD, ${ }^{*}$ Yoshihiko Watanabe MD, $\dagger$ Keisuke Amaha MD, * Yasuaki Hosaka MD, $\ddagger$ Suguru Takagi MD $\ddagger$
Haemodynamic responses to the apnoea test for the diagnosis of brain death were investigated in nine patients with severe hend injury or cerebrovascular disense. To prove apnoen, the ventilator was disconnected for ten minutes and oxygen was insufflated to avoid hypoxaemia. No respiratory movement was seen in any patient. Ten minutes after discomecting the ventilator, $\mathrm{PaCO}_{2}$ was increased to $78 \pm 3 \mathrm{mmHg}$ and $\mathrm{pH}$ was reduced to $7.17 \pm 0.02$. Adequate oxygenation was maintained in all patients. Cardiac output increased from $4.8 \pm 0.7105 .7$ $\pm 0.8 \mathrm{~L} \cdot \mathrm{min}^{-1}(P<0.05)$, and mean pulmonary artery pressure increased from $l l \pm 1$ to $17 \pm 2 \mathrm{mmHg}(P<0.01)$. However, mean arterial pressure, heart rate, pulmonary artery wedge pressure and right atrial pressure did not change. Plasma catecholamines were measured in three patients. Plasma norepinephrine concentrations increased in all three patients but the changes in plasma epinephrine were minimal. These circulatory responses to acule hypercapnia were less than those reported in awake volunteers and in patients during general anaesthesia. However, since plasma norepinephrine concentration increased during the test, some sympathoadrenal response, probably of spinal origin, was preseit, and may have prevented the direct depressant circulatory effects of acute hypercapnia. In conclusion, the apnoea test did not produce haemodynamic disturbances when respiratory acidosis was limired to a pH $7.17 \pm 0.02$ and $\mathrm{PaCO}_{2} 60-80 \mathrm{mmHg}$.

\section{Key words}

BRAIN: death;

CARBON DIOXIDE: hypercapnia.

From the *Department of Anesthesiology and Critical Care Medicine, School of Medicine, Tokyo Medical and Dental University, 1-5-45, Yushima, Bunkyo-ku, Tokyo, Japan; and the †Departments of Anesthesiology and $¥$ Neurosurgery, Tokyo Metropolitan Hiroo General Hospital, 2-34-10, Ebisu, Shibuya-ku, Tokyo, Japan.

Address correspondence 10: Dr. T. Ebata.

Accepted for publication I8ih Jamuary, 1991.
Lors de l'établissement du diagnostic de mort cérébrale chez neuf pacients victimes de rraumatisme ou de maladie cérébrovasculaire, nous avons mesuré la réponsé hémodynamique au rest d' apnée. Le ventilateur érair débranché pendanr dix minures alors qu'on insufflait de l'oxygène afin d'éviler l'hyporémie. Aucun patient ne fit de mouvement respiratoire et an bout de dix minutes la $\mathrm{PaCO}_{2}$ éfair de $78 \pm 3 \mathrm{mmHg}$ alors que le $\mathrm{pH}$ étair de $7,17 \pm 0,02$ et que chez tous, l'orygénation était adéquate. Le débil cardinque passa de 4,8 40,7 ì $5,7 \pm 0,8 \mathrm{~L} \cdot \mathrm{min}^{-1}(P<$ $0,05)$ et la pression moyenne de l'artère pulmonaire de $I I \pm I$ à $17 \pm 2 \mathrm{mmHg}(P<0,01)$. La tension artérielle systémique, le pouls, la pression pulmonaire capillaire bloquée et la pression de l'oreillette droite restèrent les mêmes. Nous avons mesuré les niveaux de cathécolamines plasmatiques chez trois patients et avons identifié une petite angmentation de la noradrénaline chez tous trois lors du test (NS) alors que l'adrénaline, elle. variait très peu. L'amplitude de la réponse hémodynamique à une hypercarbie aiguë mesurée dans notre élude est beaucoup moindre que celle notée chez des volontuires conscients on chez des patients sous anesthésie générale. L'angmentation, limitée cerles, de la noradrénaline plasmatique indique tourefois qu' il persistait une certaine réponse sympathoadrénergique, probablement d'origine spinale, powvant contrecarrer l'effet dépres. seur direct de l'hypercarbie aiguë sur la circulation. Bref. le test d'apnée n'entraîne pas de perurbations hémodynamiques lorsque l'acidose respiratoire se limite id un pH de 7,17 $\pm 0,02$ et di une $\mathrm{PaCO}_{2}$ entre 60 et $80 \mathrm{mmHg}$.

Apnoea testing for the diagnosis of brain death is performed by disconnecting the ventilator for long enough to allow hypercapnia to stimulate the brain stem. Studies of circulatory responses to acute hypercapnia in normal man showed that the direct depressant effects of respiratory acidosis are counteracted by the increased sympathetic tone resulting in increased blood pressure, heart rate and cardiac index. 1,2 However, under certain circumstances where the sympathetic response is impaired, such as brain death, acute hypercapnia may induce circulatory depression, but there are no data available on the haemodynamic changes which occur during the apnoea test. The purposes of this study were to determine the haemodynamic 
TABLE I Patient characteristics

\begin{tabular}{lllll}
\hline Patient & Age \& se. & Diagnosis & $B T\left(^{\circ} \mathrm{C}\right)$ & $\begin{array}{l}\text { Vusopressors } \\
\left(\mu g \cdot k g^{-1} \cdot m^{-1}\right)^{-1}\end{array}$ \\
\hline 1 & $54 \mathrm{M}$ & HI & 35.6 & DOA 10 \\
2 & $54 \mathrm{M}$ & SAH & 35.4 & DOA 15 \\
3 & $59 \mathrm{~F}$ & SAH & 34.0 & DOA 25, DOB 25 \\
4 & $78 \mathrm{M}$ & SAH & 37.0 & DOA 20 \\
5 & $45 \mathrm{M}$ & ICH & 36.8 & DOA 10 \\
6 & $57 \mathrm{M}$ & SAH & 36.8 & DOA 30, DOB 30 \\
7 & $48 \mathrm{M}$ & HI & 37.4 & DOA 17 \\
8 & $38 \mathrm{~F}$ & ICH & 35.8 & DOA 5 \\
9 & $48 \mathrm{M}$ & SAH & 35.0 & DOA 30 \\
\hline
\end{tabular}

HI: head injury, SAH: subarachnoid hacmorrhage, ICH: intracranial haemorrhage, BT: body temperature when the study was performed, DOA: dopamine, DOB: dobutamine.

responses to acute hypercapnia during the apnoea test and to assess the safety of the test.

\section{Methods}

The study was approved by and carried out according 10 the instructions of the Ethics Committee of Tokyo Metropolitan Hiroo General Hospital. Nine patients with severe head injury or cerebrovascular disease were studied (Table I). Their ages ranged from 38 to $78 \mathrm{yr}$ (mean, 53.4). Informed consent to the study was given by their families before the diagnosis of brain death. The lungs of the patients were ventilated mechanically and vasopressors were given continuously. The diagnosis of brain death was performed according to a protocol recommended by the Japanese Ministry of Public Welfare. The criteria of brain death were deep coma, loss of brain stem reflexes, isoelectrical EEG and persistent apnoea in the absence of hypothermia and CNS depressant drugs. All patients fulfilled these criteria except for the absence of spontaneous breathing which was to be confirmed by the apnoea test. Prior to the test, a F.5-Fr pulmonary artery catheter (93A831, Baxter Edwards Laboratories) was inserted via either the subclavian or right internal jugular vein for haemodynamic measurements, and a 20-ga arterial catheter was inserted into a radial artery for blood sampling and continuous blood pressure monitoring.

Apnoea was tested with the method described by Pallis. ${ }^{3}$ The lungs were ventilated with $100 \%$ oxygen, and then the rate of ventilation was slowed to increase the initial value of $\mathrm{PaCO}_{2}$ to approximately $45 \mathrm{mmHg}$. After confirming that the patient was not hypoxic, the apnoea test was carried out by disconnecting the ventilator for ten minutes. In order to prevent hypoxia, oxygen was insufflated at the rate of $6 \mathrm{~L} \cdot \mathrm{min}^{-1}$ via a suction catheter (ID $2.1 \mathrm{~mm}$ ) inserted through the endotracheal tube. The tip of the catheter was placed $2-5 \mathrm{~cm}$ above the carina.
Dopamine was given to all patients and dobutamine was also given to two patients to preserve organ perfusion, because all the patients became hypotensive within a few hours after they had lost brain stem reflexes. The infusion rates of these vasopressors are shown in Table I and were kept constant during the test. Apnoea was established by confirming that no respiratory movements occurred during the ten minutes off the ventilator. At the end of the test, arterial blood gas analysis was performed to confirm that an adequate level of $\mathrm{PaCO}_{2}$, which was expected to be $>60 \mathrm{mmHg}$ to stimulate the respiratory centre, had been reached.

Blood pressure (BP), mean pulmonary artery pressure (MPAP) and heart rate (HR) were measured throughout the study, and the values at the beginning and at the end of the test were taken as the pre- and post-apnoea test values. Cardiac output ( $\mathrm{CO}$ ), at end expiration, was measured by the thermodilution technique before and immediately after the apnoea test, and the mean of three measurements was used. Pulmonary capillary wedge pressure (PCWP) and right atrial pressure (RAP) were measured at the beginning and immediately before the end of the test while the ventilation was ceased. Systemic vascular resistance (SVR) and pulmonary vascular resistance (PVR) were calculated by standard formulae.

In three patients, the concentrations of plasma norepinephrine and epinephrine were measured on four occasions, (1) on admission to the ward in the state of impending brain death, (2) after the patients had lost brain stem reflexes and when BP decreased suddenly prior 10 the initiation of dopamine infusion, (3) after the infusion of dopamine was started and immediately before the apnoea test, (4) immediately after the apnoea test. After centrifugation, plasma was stored at $-20^{\circ} \mathrm{C}$ until assayed. Plasma norepinephrine and epinephrine concentrations were measured by high-performance liquid chromatography.

All values are presented as the mean \pm SEM. Student's paired $t$ test was used to compare the blood gas, haemodynamic and plasma catecholamine data before and after the apnoea test, and plasma catecholamine concentrations on admission to the ward in the state of impending brain death and after the patients lost brain stem reflexes and became hypotensive. $P$ values $<0.05$ were considered to be statistically significant.

\section{Results}

None of the patients showed spontaneous respiratory movements during apnoea testing. The $\mathrm{PaCO}_{2}$ increased from $45 \pm 1$ to $78 \pm 3 \mathrm{mmHg}(P<0.001)$ and was associated with $\mathrm{pH} 7.17 \pm 0.02$. Adequate oxygenation was maintained in all subjects (Table II).

The BP, HR, PCWP and RAP did not change signifi- 
TABLE II Changes in arterial blood gas and haemodynamic variables during the apnoea tesI

\begin{tabular}{lccl}
\hline & Before & Afier & $P$ \\
\hline $\mathrm{pH}$ & $7.37 \pm 0.01$ & $7.17 \pm 0.02$ & $<0.001$ \\
$\mathrm{PaCO}_{2}(\mathrm{mmHg})$ & $45 \pm 1$ & $78 \pm 3$ & $<0.001$ \\
$\mathrm{PaO}_{2}(\mathrm{mmHg})$ & $373 \pm 46$ & $332 \pm 38$ & $\mathrm{NS}$ \\
$\mathrm{BE}\left(\mathrm{mEq} \cdot \mathrm{L}^{-1}\right)$ & $0.4 \pm 1.2$ & $-2.3 \pm 1.3$ & $<0.001$ \\
$\mathrm{MAP}(\mathrm{mmHg})$ & $80 \pm 5$ & $81 \pm 7$ & $\mathrm{NS}$ \\
$\mathrm{HR}(\mathrm{bpm})$ & $100 \pm 7$ & $100 \pm 7$ & $\mathrm{NS}$ \\
$\mathrm{MPAP}(\mathrm{mmHg})$ & $11 \pm 1$ & $17 \pm 2$ & $<0.01$ \\
$\mathrm{PCWP}(\mathrm{mmHg})$ & $5 \pm 1$ & $5 \pm 1$ & $\mathrm{NS}$ \\
$\mathrm{RAP}(\mathrm{mmHg})$ & $3 \pm 1$ & $3 \pm 1$ & NS \\
SVR $\left(\right.$ dyn $\left.\cdot \mathrm{sec} \cdot \mathrm{cm}^{-5}\right)$ & $1560 \pm 252$ & $1387 \pm 259$ & $\mathrm{NS}$ \\
PVR (dyn'sec $\left.\cdot \mathrm{cm}^{-5}\right)$ & $112 \pm 23$ & $183 \pm 37$ & $\mathrm{NS}$ \\
$\mathrm{CO}\left(\mathrm{L} \cdot \mathrm{min}^{-1}\right)$ & $4.8 \pm 0.7$ & $5.7 \pm 0.8$ & $<0.05$ \\
\hline
\end{tabular}

MAP: mean arterial pressure, HR: heart rale, MPAP: mean pulmonary arery pressure, PCWP: pulmonary capillary wedge pressure, RAP: right atrial pressure, SVR: systemic vascular resislance, PVR: pulmonary vascular resistance, $\mathrm{CO}$ : cardiac outpul.

cantly during the test. However, MPAP $(P<0.01)$ and $\mathrm{CO}(P<0.05)$ were increased at the end of the test. The SVR was slightly decreased and PVR increased, but the changes were not statistically significant (Table II). No arrhythmias were observed throughout the test.

Both plasma norepinephrine and epinephrine concentrations showed initial high values in the state of impending brain death. When brain stem reflexes were lost and the BP suddenly decreased, these values decreased, though the change in plasma epinephrine was not statistically significanı (Table III). The level of plasma norepinephrine was restored to some extent after dopamine administration was started. During the apnoea lest, plasma norepinephrine concentration increased in all three patients, but the difference did not reach statistical significance. On the contrary, plasma epinephrine concentrations showed minimal changes (Table III).

\section{Discussion}

The haemodynamic responses to increases in $\mathrm{PaCO}_{2}$ are complex, and are made up of the direct effects of carbon dioxide-induced changes in blood $\mathrm{pH}$ and the secondary effects mediated by the central and autonomic nervous systems. Carbon dioxide dilates peripheral arterioles and depresses myocardial contractility by direct action. ${ }^{4}$ In addition, hypercapnia, mainly via the central nervous system, increases sympathetic tone, and thereby antagonizes the direct depressant effects of carbon dioxide on myocardial contractility and vascular tone. The overall circulatory response to hypercapnia is a balance between these direct and indirect effects.

In awake volunteers, an increase in $\mathrm{PaCO}_{2}$ of 50 to 100 $\mathrm{mmHg}$ is associated with increases in $\mathrm{BP}, \mathrm{HR}$ and $\mathrm{CO}$ and a decrease in SVR. ${ }^{1,2}$ During general anaesthesia, however, sympathoadrenal responses to carbon dioxide are modified. Price et al. reported that the extent of increases in $\mathrm{BP}$ and $\mathrm{HR}$ with $\mathrm{PaCO}_{2}$ in anaesthetized patients were reduced by one-half with cyclopropane and by two-thirds with halothane compared with values observed in awake volunteers. ${ }^{5}$ They suggested that the mechanisms responsible for the reduction in the normal haemodynamic responses by those general anaesthetics included abolition of the feelings of anxiety and suffocation caused by hypercapnia and, especially in case of halothane, the depressant effects of the drug itself on central and autonomic nervous systems induced a decrease in the sympathoadrenal responses to hypercapnia.

General anaesthetics such as cyclopropane and halothane increase the susceptibility of the heart to catecholamines and induce cardiac arrhythmias in the presence of hypercapnia. During total spinal block in dogs, $\mathrm{CO}_{2}$ inhalation caused marked hypotension and a decrease in $\mathrm{CO}^{6}$ These findings indicate the potential danger of acute hypercapnia in certain disease states. During the apnoea test for the diagnosis of brain death, BP and HR show minimal changes. ${ }^{7,8}$ However, there are few studies which have investigated in detail the haemodynamic changes that occur during the test. ${ }^{9}$

In the present study, CO and MPAP increased, but other variables did not change. The $B P$ and $H R$ responses to changes in $\mathrm{PaCO}_{2}$ observed in brain-dead patients of the present study are compared in the Figure with those

TABLE III Changes in plasma norepinephrine and epinephrine concentrations in three patients

\begin{tabular}{llllc}
\hline & $(1)$ & $(2)$ & (3) & (4) \\
\hline Norepinephrine $\left(\mathrm{pg} \cdot \mathrm{ml}^{-1}\right)$ & $1856 \pm 315$ & $413 \pm 177^{*}$ & $963 \pm 336$ & $1393 \pm 569$ \\
Epinephrine $\left.(\mathrm{pg} \cdot \mathrm{ml})^{-1}\right)$ & $836 \pm 332$ & $36 \pm 6$ & $49 \pm 15$ & $66 \pm 36$ \\
\hline
\end{tabular}

(1) On admission to the ward in the state of impending brain death.

(2) Sudden decrease in BP.

(3) Immediately before apnoea test.

(4) Immediately after apnoea test.

*Statistically significant compared with (1) $(P<0.05)$. 


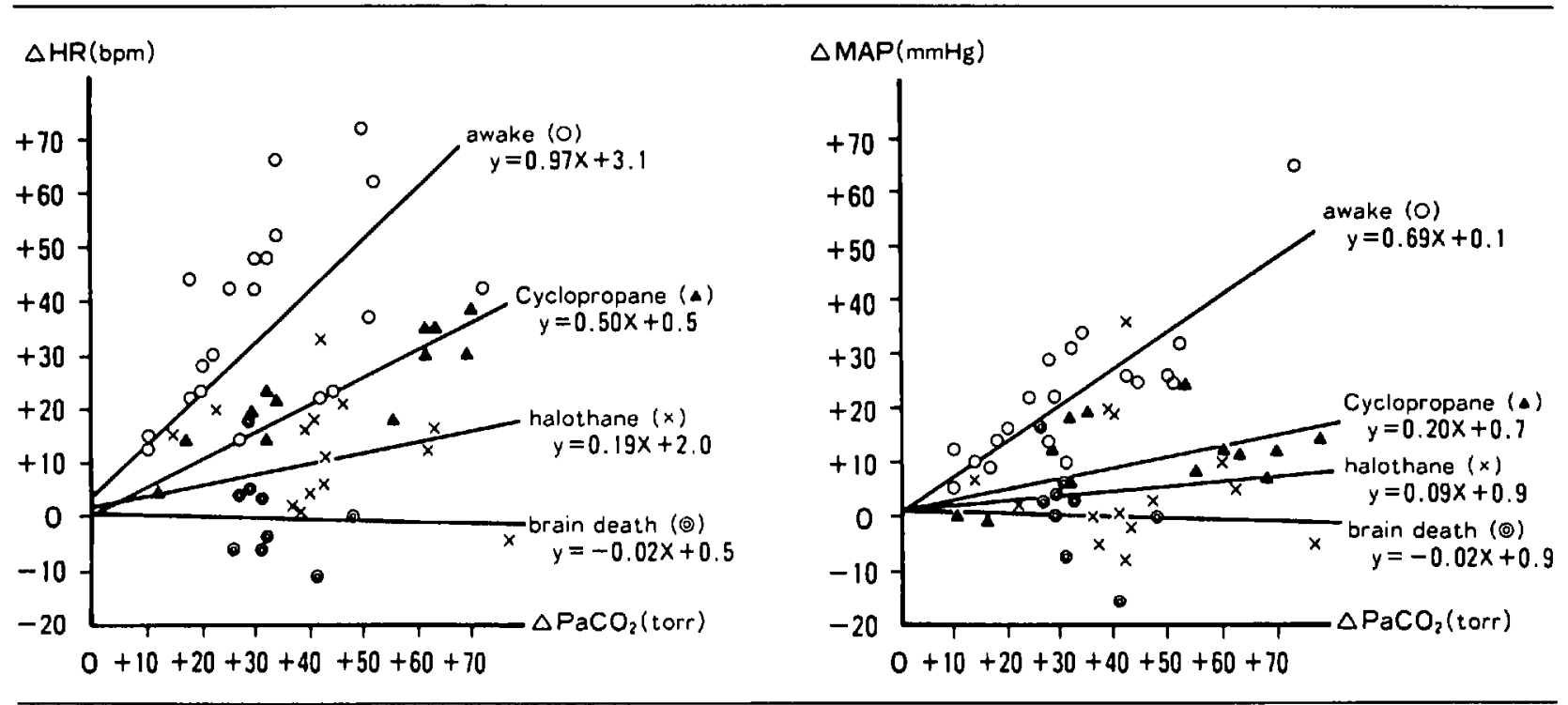

FIGURE Effects of hypercapnia on changes in heart rate (HR) and mean arterial pressure (MAP). Comparison of responses in brain dead patients (O) from those in awake volunteers $(O)$ and patients receiving cyclopropane $(\Delta)$ and halothane $(x)$. Data of the latter were drawn from Price et al..$^{5}$

found in normal awake volunteers and in patients during general anaesthesia reported by Price. ${ }^{5}$ In the brain-dead patients, the circulatory depression described in dogs during total spinal block did not occur, although the circulatory stimulating response was markedly depressed compared with those in volunteers and patients under general anaesthesia. The $\mathrm{CO}$ increased in the present study, but less than that observed in conscious subjects. Cullen and Eger' analyzed the cardiovascular response to $\mathrm{CO}_{2}$ in awake subjects and showed that an increase in $\mathrm{PaCO}_{2}$ of $1 \mathrm{mmHg}$ was associated with an increase in $\mathrm{CO}$ of $0.17 \mathrm{~L} \cdot \mathrm{min}^{-1}$. In brain-dead patients of the present study, the increase in $\mathrm{CO}$ was $0.05 \mathrm{~L} \cdot \mathrm{min}^{-1}$ per $\mathrm{mmHg}$ $\mathrm{PaCO}_{2}$. The rise in MPAP was correlated with the increase in PVR in this study $(r=0.72, P<0.05)$. Therefore, pulmonary vasoconstriction due to respiratory acidosis $^{10}$ may have been the primary reason for the increase in MPAP. Other mechanisms, such as increases in plasma norepinephrine concentration and $\mathrm{CO}$ may also have contributed to the increase in MPAP.

Disappearance of brain stem reflexes and decrease in blood pressure were associated with decreases of plasma norepinephrine and epinephrine concentrations in all three patients in whom changes of plasma catecholamine were measured, although the change in plasma epinephrine was not statistically significant. These changes may reflect either decreased or depleted release of catecholamines from the central nervous system. Dopamine is a precursor of norepinephrine and epinephrine and it is reported that approximately $25 \%$ of dopamine administered is used for norepinephrine synthesis."
Furthermore, dopamine may enhance plasma norepinephrine concentration by the release of endogeneous norepinephrine. ${ }^{12}$ Therefore, the restoration of plasma norepinephrine concentrations at the beginning of the apnoea test may have been due to the dopamine infusion. During the apnoea test, plasma norepinephrine concentration increased in all three patients, though statistical significance was not reached. We considered that this failure in proving statistical difference was attributed to the small number of the patients and large variations of plasma catecholamine concentrations among individuals. Therefore, we presume that the increase in plasma norepinephrine seen during the test was related to the acute hypercapnia, because the infusion rate of dopamine was kept constant. On the contrary, the plasma epinephrine concentration did not change and remained low during the test. In animal studies, the response of plasma epinephrine to hypercapnia was demonstrated only at higher levels of $\mathrm{PaCO}_{2}$ than in the present study. ${ }^{13}$

Wetzel et al. observed tachycardia and hypertension in response to abdominal incision for nephrectomy in brain dead organ donors, and suggested the existence of intact spinal reflex arcs between pain and sympathetically mediated efferents. ${ }^{14}$ Similarly, the increase in plasma norepinephrine concentration in response to hypercapnia which was seen in this study may have occurred without involving the brain stem vasomotor centre. The existence of spinal cardiovascular centres is proved in animals and which increase the sympathetic outflow to the cardiovascular system in response to acute changes in blood gas in spinal cats. ${ }^{15}$ Therefore, the sympathoadrenal responses 
to acute hypercapnia seen in brain-dead patients in this study might also have been mediated by the spinal cardiovascular centres.

In conclusion, the apnoea test for the diagnosis of brain death is without haemodynamic disturbance if the increase of $\mathrm{PaCO}_{2}$ is limited to around $60 \mathrm{mmHg}$. Some sympathoadrenal response to hypercapnia is preserved which counteracts the direct circulatory depressant effect of carbon dioxide.

\section{References}

1 Cullen DJ, Eger /I El. Cardiovascular effects of cabon dioxide in man. Anesthesiology 1974; 41: 345-9.

2 Sechzer PH, Egbert LD, Linde HW, Cooper DY, Dripps $R D$, Price $H L$. Effect of $\mathrm{CO}_{2}$ inhalation on arterial pressure, ECG and plasma catecholamines and $17-\mathrm{OH}$ corticosteroids in normal man. J Appl Physiol 1960; 15 : 454-8.

3 Pallis $G$. ABC of brain stem death, Diagnosis of brain stem death II. BMJ 1982; 285: 164I-4.

4 Price $H L$. Effects of carbon dioxide on the cardiovascular system. Anesthesiology 1960; 21: 652-63.

5 Price HL, Lurie AA, Black GW. Sechzer PH, Linde HW, Price ML. Modification by general anesthetics (cyclopropane and halothane) of circulatory and sympathoadrenal responses to respiratory acidosis. Ann Surg 1960; 152: 1071-7.

6 Kimura $K$. Experimental studies on cerebro-spinal anesthesia. Masui 1978; 27: 1059-70.

7 Belsh JM, Blatt R, Schiffman PL. Apnea testing in brain death. Arch Intern Med 1986; 146: 2385-8.

8 Pitss LH, Kaktis J, Caronna J, Jennet S, Hoff JT. Brain death, apneic diffusion oxygenation, and organ transplantation. J Trauma 1978; 18: 180-3.

9 Ohno $M$. Cardiovascular effects of apnea test in the diagnosis of brain death. Masui 1990; 39: 822-6.

10 Bergofsky EH, Lehr DE, Fishman AP. The effect of changes in hydrogen ion concentration on the pulmonary circulation. J Clin Invest 1962; 41: 1492-502.

11 Goodall $M c C$, Alton H. Metabolism of 3-hydroxytyramine (dopamine) in human subjects. Biochem Pharmacol 1968; 17: 905-14.

12 Kho TL, Henquet JW, Pumt R, Birkenhager WH, Rahn $K H$. Influence of dobutamine and dopamine on hemodynamics and plasma concentrations of noradrenaline and renin in patients with low cardiac output following acute myocardial infarction. Eur J Clin Pharmacol 1980; 18: 213-7.
13 Millar RA. Plasma adrenaline and noradrenaline during diffusion respiration. J Physiol 1959; I50: 79-90.

14 Wetzel RC, Setzer N, Stiff JL, Rogers MC. Hemodynamic responses in brain dead organ donor patients. Anesth Analg 1985; 64; 125-8.

15 Alexander RS. The effects of blood flow and anoxia on spinal cardiovascular centres. Am J Physiol 1945; 143 : 698-705. 